\title{
Otitis media aguda
}

\author{
Dra. Solange Caussade'
}

1 Profesor Asistente Adjunto. División Pediatría. Pontificia Universidad Católica de Chile.

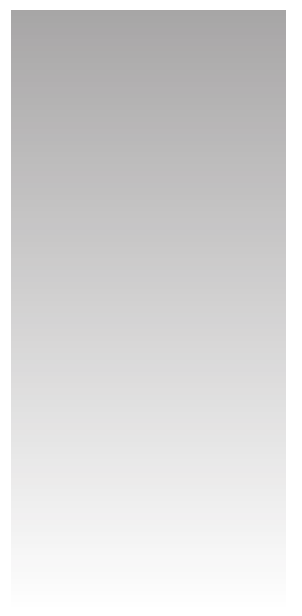

\section{ACUTE OTITIS MEDIA}

We review differents topics about acute otitis media without complication. There is a frequent cause of visit to pediatric office. We showed risk factors, to consider how to prevent it. As viral infection are frequent cause there is not necessary to start antibiotics. Finally we describe complications as otitis effusion

Key words: Acute otitis media, etiology, treatment, children.

\section{RESUMEN}

Se revisan diversos aspectos de la otitis media aguda no complicada, causa muy frecuente de consulta en nuestra práctica pediátrica. Se mencionan sus factores de riesgo, que constituyen los principales elementos a considerar para su prevención. Debido a la frecuente etiología viral, la conducta terapéutica actual considera en ciertas situaciones postergar el inicio del tratamiento antibiótico. Finalmente se describen sus complicaciones, siendo la más frecuente la efusión en oído medio.

Palabras clave: Otitis media aguda, etiología, tratamiento, niños.

\section{INTRODUCCIÓN}

La otitis media aguda (OMA) es la infección aguda del oído medio que se caracteriza por la presencia de líquido en el oído medio asociado a cambios inflamatorios ${ }^{(1,2)}$. Es una de las causas más frecuentes de consulta y de uso de antibióticos ${ }^{(3-5)}$. La prevalencia más alta afecta a los niños entre 6 meses y 2 años. A los 2 años de vida más del 70-80\% de los niños ha presentado un episodio y cerca del 20-50\% tres o más episodios de $O M A^{(6)}$.

\section{FACTORES DE RIESGO}

El factor de riesgo más importante es la edad. Además se incluyen: sexo masculino, historia familiar de OMA, ausencia de lactancia materna o corta duración de esta ( $<$ de 3 meses), uso de chupete, alimentación con fórmula (especialmente en posición supino al acostarse), tabaquismo, asistencia a sala cuna, raza, nivel socio-económico, anomalías craneofaciales tales como fisura palatina y presencia de atopia ${ }^{(1,3,5,7)}$.

Correspondencia: Solange Caussade. Pediatra Broncopulmonar. Profesor Asistente Adjunto. División Pediatría. Pontificia Universidad Católica de Chile.

Lira 85 5to piso. Santiago Centro.

Teléfono: 23543767.

E-mail: solangecaussade@gmail.com

ISSN 07|8-332| Derechos reservados.

\section{ETIOPATOGENIA}

La susceptibilidad de los niños pequeños para desarrollar OMA se explica por la falta de inmunidad protectora, que no es eficiente en la producción de anticuerpos específicos para agentes capsulados ${ }^{(1)}$. En forma adicional son importantes las características anatómicas de la trompa de Eustaquio, la que es más corta, horizontal y menos funcional, lo que permite el ascenso de agentes patógenos provenientes de la nasofaringe hasta el oído medio ${ }^{(7)}$. La colonización con agentes patógenos es uno de los elementos fundamentales para el desarrollo de OMA. A los 4 meses el 50\% de los niños está colonizado por al menos un agente patógeno, y al año de vida la frecuencia de colonización asciende hasta el $70-80 \%{ }^{(7)}$. En niños que cursan una OMA, el cultivo de líquido en oído medio obtenido por timpanocentesis muestra la presencia de bacterias en un $55 \%$ y en un $15 \%$ bacterias y virus( ${ }^{(8)}$. Los agentes bacterianos más frecuentes son $S$. pneumoniae, $H$. influenzae no tipificable y $M$. catarrhalis $^{(1,5)}$. Estudios extranjeros utilizando técnicas de PCR muestran que los virus están presentes en el 48-72\% de las OMA, siendo el más frecuentemente encontrado el virus respiratorio sincicial y en forma decreciente virus parainfluenza, influenza, enterovirus y adenovirus. Menos frecuentes son rinovirus, coronavirus y metaneumovirus ${ }^{(6)}$. En nuestro país, se realizó un estudio mediante punción timpánica dirigido a detectar principalmente la etiología bacteriana de OMA que mostró: S. pneumoniae; (40\%), H. influenzae no tipificable (29\%), S. pyogenes (7\%) y $M$. catarrhalis $(4 \%)^{(9)}$. 


\section{MANIFESTACIONES CLÍNICAS}

Los síntomas de la OMA comienzan luego de tres días de evolución de una infección respiratoria aguda alta de origen viral e incluyen: otalgia, fiebre e hipoacusia intermitente (sensación de oído tapado). Los lactantes generalmente presentan primero irritabilidad, rechazo alimentario, llanto persistente, alteración del sueño y en ocasiones vómitos. Ocasionalmente se presenta como fiebre persistente $u$ otorrea repentina. Al examen otoscópico se observa el tímpano opaco, eritematoso, abombado y con bulas; cuando la OMA ha progresado hacia la perforación timpánica se hace evidente la otorrea purulenta y la mejoría significativa de los síntomas generales. La otoscopía neumática permite detectar efusión en el oído medio al mostrar disminución o abolición de la movilidad timpánica. La punción timpánica diagnóstica (y terapéutica) sólo se indica ante una falta de respuesta a tratamiento a las 48-72 $\mathrm{h}$ de instaurado $(2,3,5,8)$.

\section{Tratamiento}

El año 2004 la Academia Americana de Pediatría recomienda la indicación de terapia antibacteriana en todo menor de 6 meses, aún con diagnóstico incierto de OMA $\mathrm{A}^{(2)}$. Esta recomendaba también el inicio de terapia antibacteriana en los niños de 6 meses a 2 años sólo con diagnóstico de certeza de OMA. En la actualización del año $2013^{(8)}$ a esta edad se da a elegir entre el inicio de terapia y la observación, en los que presentan OMA unilateral asociada a síntomas leves. Esto se basa en evidencia acerca de la seguridad en observar o postergar el inicio del tratamiento en estos pacientes. Se ha descrito además la resolución espontánea de la infección bacteriana $^{(8)}($ Tabla I).

\section{Definiciones utilizadas para definir tratamiento(8):}

I. Diagnóstico de certeza de OMA: existen 2 situaciones:

- Presencia de abombamiento importante de la membrana timpánica u otorrea no debida a otitis externa.

- Presencia de abombamiento leve de la membrana timpánica y menos de $48 \mathrm{~h}$ de otalgia (lactante frota su oreja), o eritema intenso de la membrana timpánica.

2. Enfermedad no severa: otalgia leve por menos de 48 h y fiebre $<39^{\circ} \mathrm{C}$.

3. Enfermedad severa: otalgia moderada a severa u otalgia por al menos $48 \mathrm{~h}$ o fiebre $\geq 39^{\circ} \mathrm{C}$.

El antibiótico de primera línea es la amoxicilina, basado en su seguridad y eficacia para erradicar $S$. pneumoniae de la cavidad del oído medio. La dosis sugerida es 80-90 mg/kg/día en 2 dosis. En lactantes, pre-escolares y en niños de cualquier edad con signos de severidad la duración del tratamiento debe ser de 10 días. En mayores de 6 años con enfermedad leve a moderada la duración se puede acortar a 7 días ${ }^{(2,8)}$. Al elegir el antibiótico hay que considerar la posibilidad de la presencia de un agente infeccioso resistente, siendo los principales factores de riesgo el uso de antibiótico los 30 días previos y la asistencia a sala cuna ${ }^{(2,8)}$. En pacientes con alergia a amoxicilina (no hipersensibilidad tipo I) está indicado cefuroximo $30 \mathrm{mg} / \mathrm{kg} / \mathrm{día}$ en 2 dosis. En caso de alergia tipo I se usa claritromicina $15 \mathrm{mg} / \mathrm{kg} / \mathrm{día}$ en 2 dosis o azitromicina $10 \mathrm{mg} / \mathrm{kg} /$ día por I día luego $5 \mathrm{mg} / \mathrm{kg} /$ día por 4 días. Si el paciente presenta vómitos: ceftriaxona $50 \mathrm{mg} / \mathrm{kg} /$ día por 3 días ${ }^{(2,8)}$. En caso de no haber respuesta a tratamiento a las 48$72 \mathrm{~h}$ también está indicado el uso de ceftriaxona $50 \mathrm{mg} / \mathrm{kg} / \mathrm{d}$ ía por I a 3 días, y eventualmente timpanocentesis diagnóstica y terapéutica ${ }^{(2,8)}$.

Tratamiento del dolor: debe usarse a partir de las primeras $24 \mathrm{~h}$ de enfermedad, independiente del uso de antibióticos. Por su disponibilidad y mostrar analgesia efectiva en casos de dolor leve y moderado los más usados son el paracetamol e ibuprofeno ${ }^{(2,8)}$. El uso de descongestionantes y antialérgicos no ha demostrado eficacia en acortar la duración de síntomas, prevenir cirugía ni de complicaciones, y tienen alto riesgo de aparición de efectos colaterales ${ }^{(2)}$.

\section{EVOLUCIÓN}

Habitualmente a las 48-72 h de tratamiento el niño mejora (desaparece la fiebre, mejoran las condiciones generales: apetito, irritabilidad, patrón de sueño). Luego de dos semanas de un episodio de OMA el 60-70\% presenta efusión (OME), lo que disminuye al mes a un $40 \%$ y a los 3 meses entre $10-25 \%(2,8)$.

\section{COMPLICACIONES}

El 5\% de los pacientes presenta perforación timpánica, la que representa la complicación más frecuente. Aunque la perforación contribuye a la mejoría espontánea de la OMA, se debe asegurar la erradicación del agente patógeno si se sospecha una bacteria, y evitar la humedad local de modo de favorecer la cicatrización espontánea de la membrana timpánica ${ }^{(5)}$. Como ya se mencionó, la efusión en el oído medio puede persistir, lo que puede determinar retraso en el desarrollo del lenguaje debido a hipoacusia ${ }^{(3)}$. La presencia de líquido

Tabla I. Tratamiento ${ }^{(8)}$

\begin{tabular}{|lcccc|}
\hline Edad & $\begin{array}{c}\text { Otorrea unilateral con } \\
\text { OMA }\end{array}$ & $\begin{array}{c}\text { OMA uni o bilateral con } \\
\text { síntomas severos }\end{array}$ & $\begin{array}{c}\text { OMA bilateral sin } \\
\text { otorrea }\end{array}$ & OMA sin otorrea \\
\hline 6 meses a 2 años & Antibiótico & Antibiótico & Antibiótico & Antibiótico u observación \\
$\geq 2$ años & Antibiótico & Antibiótico & Antibiótico u observación & Antibiótico u observación \\
\hline
\end{tabular}

*La opción de observar al paciente sólo se realizará si se puede seguir su evolución, y deben iniciarse antibióticos en caso de persistencia o agravamiento de los síntomas dentro de un plazo de 48-72 h de inicio de la enfermedad. 
en oído medio también puede ser causa de otitis media recurrente o crónica ${ }^{(8)}$. Las complicaciones graves son muy infrecuentes, siendo la más habitual la mastoiditis( ${ }^{(1)}$. Otras complicaciones graves son: laberintitis, meningitis, encefalitis focal, absceso cerebral, subdural o extradural, parálisis facial(5).

\section{PREVENCIÓN}

Evitar la asistencia a sala cuna, evitar exposición a tabaco, fomento de lactancia materna hasta los 6 meses y evitar el chupete y mamadera. Aunque la vacuna conjugada para neumococo (PCV7) disminuye en menos de un 10\% la incidencia de OMA esto tiene impacto debido a la alta prevalencia de esta enfermedad en lactantes. Aún no se han reportado datos relacionados con $\mathrm{PVI} 3^{(2,7,8)}$

\section{CONCLUSIÓN}

La OMA aún es aún una enfermedad altamente prevalente en especial en niños menores. Las guias de tratamiento actuales sugieren limitar el uso de antibióticos ya que no siempre son beneficiosos y por otro lado se contribuye a aumentar su resistencia. El diagnóstico clínico de certeza es el factor determinante para definir la conducta terapéutica correcta.

\section{REFERENCIAS}

I. Corbeel L. What is new in otitis media? Eur J Pediatr 2007; 166: $5 \mid 1-9$.

2. Academy of Pediatrics Subcommittee on Management of Acute Otitis Media. Diagnosis and management of acute otitis media. Pediatrics 2004; I 13: | 45 I-5.

3. Gunasekera H, Morris P, Mclntyre P, Craig J. Management of children with otitis media: A summary of evidence from recent systematic reviews. J Pediatr Child Health 2009; 45: 554-63.

4. Rovers M, Glasziou P, Appelman C, Burke P, McCormick D, et al. Predictors of pain and/or fever at 3 to 7 days for children with acute otitis media not treated initially with antibiotics: a meta-analysis of individual patient data. Pediatrics 2007; I 19: 579-85.

5. Siegel R, Bien J. Acute otitis media in children: a continuying story. Pediatr Rev 2004; 25: 187-92.

6. Heikkinen T, Chonmaitree T. Importance of respiratory virus in acute otitis media. Clin Microbiol Rev 2003; 16: 230-4I.

7. Pelton S, Leibovitz E. Recent advances in otitis media. Pediatr Infect Dis 2009; 28: SI33-SI37.

8. Lieberthal A, Carroll a, Chonmaitree T, Ganiats T, Hoberman A, Jackson MA et al. The diagnosis and management of acute otitis media. Pediatr 2013; 131: e964-99.

9. Santolaya de P ME. Otitis media aguda: Diagnóstico y tratamiento. Rev Chil Infectol 2007; 24: 297-300. 